\title{
The Asian monsoon as a geophysical problem
}

\section{Robert M. Chervin}

Monsoon Dynamics. Edited by James Lighthill and R.P. Pearce. Pp.735. ISBN 0-521-22497-7. (Cambridge University Press: 1981.) £50, \$130.

TowARDS the end of 1977 , a large number of representatives from the different geophysical sub-disciplines gathered in New Delhi with the aim of assessing the (then) current state of understanding of the processes involved in the monsoon cycle. An equally important purpose was to provide guidance and encouragement to those members of the community with the operational responsibility for local weather and flood forccasting. Indeed, the full title of the symposium - "Monsoon Dynamics, with Applications to Weather Forecasting and Flood Prediction" - gave emphasis to this intended dual function of the meeting.

This volume, which contains edited versions of 46 of the 53 research papers presented at the meeting, is a fairly complete rccord of the symposium. The individual papers are placed in one of five sections, primarily according to the time and space scales of the particular phenomena being investigated, or to the general approach involved. Each section is preceded by two to three pages of introductory material by one of the editors which preview the subsequent papers and place their contributions within the context of the larger multi-disciplinary objects of the symposium.

In Delhi (and thus in the book) the observational papers ran a gamut from the rather straightforward descriptive presentation of the geographical distribution of rainfall patterns to some sophisticated diagnostic analyses of atmospheric energetics and wave interactions. Data culled from a variety of different observing systems - among them aircraft, ships, super-pressure balloons and sateliites - were employed. A few papers reported the results of the MONSOON-77 experiment, a precursor to the larger scale Monsoon Experiment (MONEX) which took place in 1979 as part of the Global Atmospheric Research Program (GARP). A particularly noteworthy paper was that by J.C. Sadler and J.T. Lim, which demonstrated the value of geosynchronous satellite data for determining upper troposphere level winds in the tropics - information not easily obtained from conventional observing systems.

The modelling and theoretical papers explored various interactions between the different components of the geophysical system. The models, both numerical and laboratory types of varying complexity, have been used for short-range weather and storm-surge prediction experiments, atmosphere and ocean circulation simu- lations, and climate sensitivity studies. Experiments in this Jatter category are particularly useful in assessing the impact of altered surface conditions on the dynamic and thermodynamic aspects of the monsoon. The relevance of such experiments to the real world, is of course, highly dependent on the degree to which the basic model is able to reproduce the observed climate. Notable among the modelling papers, therefore, is the intriguing contribution by the late J.G. Charney and J. Shukla. This indicates that climate prediction for the tropics may be possible with atmospheric general circulation models if proper account is taken of the variability of such boundary interfacial properties as ocean surface temperature, albedo and soil moisture.

The production quality of this volume (especially of the graphical reproductions) is for the most part superb, though a smattering of typographical errors does reduce the level below perfection. More varied is the quality of the papers themselves. Many have the appearance of being cut and pasted from other articles by the authors, and obviously they do not represent original contributions. However, the most serious criticism that may be levelled against the book is that it has appeared almost four years after the symposium took place. This lack of timeliness is made all the more apparent by our recent, enhanced appreciation of the complexities of the Asian monsoon which has resulted from the preliminary analysis of data from MONEX.

Nevertheless, within the given historical perspective, the symposium did serve an important function in focusing attention upon monsoon studies, and this volume will serve as a useful reference for those with a newly acquired interest in the Asian monsoon as a geophysical problem.

Robert M. Chervin is a Staff Scientist with the Global Climate Modeling Group at the National Center for Atmospheric Research, Boulder, Colorado. (NCAR is sponsored by the National Science Foundation).

\section{A fresh look at New World monkeys}

\section{Alan Dixson}

Ecology and Behavior of Neotropical Primates, Vol. 1. Edited by Adelmar F. Coimbra-Filho and Russell A. Mittermeier. Pp.496. (Brazilian Academy of Sciences: 1981.) \$25. Available from Dr R.A. Mittermeier, Dept Anatomical Sciences, Health Sciences Center, SUNY, Stony Brook, NY 11794.

STUDIES of the ecology and behaviour of New World primates are gathering momentum after a long period of neglect in favour of research on Old World monkeys and apes. This book, the first of two companion volumes, provides a timely and useful review of recent work. As the editors suggest, it should appeal particularly to students who are "interested in Neotropical monkeys, but do not have access to much of the published material"'.

The first section of the book is devoted to systematics and Mittermeier and Coimbra-Filho include a well-illustrated guide to the numerous species and subspecies of New World monkeys. Rosenberger deals with the higher taxa and his treatment of the historical aspects is thorough and scholarly. However, he proposes a major revision of the group whereby the marmosets and tamarins (usually placed in a distinct family, the Callitrichidae) are united with Saimiri, Cebus and Callimico in the family Cebidae, whilst all other forms are placed in the Atelidae. Many workers may judge this arrangement to be confusing and of questionable validity. The origin of the
New World monkeys also remains a controversial topic. Thus, as Rose and Fleagle point out, the fossil record is insufficient to decide whether their ancestors originated in North America or "rafted" across from Africa during the late Eocene.

Most of the book consists of chapters on individual genera and there are profiles for Callimico, Aotus, Callicebus, Saimiri, Pithecia, Chiropotes and Cacajao. Very little is known about some of these monkeys, such as the sakis and uakaris, but whenever possible the authors have included previously unpublished material in their reviews. One weakness is that little attempt is made to relate the physiological aspects of reproduction to the accounts of reproductive behaviour or seasonality. This bias in favour of field studies and observations of behaviour under natural conditions is understandable at this stage, however, particularly because many of these monkeys are endangered because of destruction of their rainforest habitat.

The second volume, still in preparation, will deal with the problem of conservation and will include detailed accounts of the remaining genera. Together, the two books should represent a valuable contribution to the literature on New World primates: I hope that libraries, research workers and students will buy them. 